\title{
SISTEM PENDUKUNG KEPUTUSAN PEMILIHAN BEASISWA DOKTOR UNTUK DOSEN POTENSIAL DENGAN METODE SMART
}

\author{
Ardi $^{1 *}$, Irfan Fadhli ${ }^{1}$ \\ ${ }^{1}$ Teknologi Informasi, Universitas Pembinaan Masyarakat Indonesia Medan \\ email:*ardyansyah35@gmail.com
}

\begin{abstract}
The role of lecturers in higher education is one of the most influential parts of the quality of students produced. Lecturer educational qualifications are also an important aspect of improving academic and institutional quality. Selection of foundation scholarships in the form of doctoral education currently has problems in choosing prospective lecturers. In the selection of doctoral scholarships for potential lecturers, there is still subjectivity in their selection manually. As a supporting medium in determining the selection of potential lecturers to obtain doctoral education foundation scholarships and testing the SMART (Simple Multi Attribute Rating Technique) method to provide scholarship recommendations for prospective lecturers. The selection process uses the SMART method because this method is able to solve multi-criteria problems from the foundation, in this case the Chancellor of the Indonesian Community Development University. Furthermore, the criteria are processed using an application built using the PHP and MySQL programming languages to test these criteria. From the application built, it can be concluded that Yuanita, M.Si with a score of 0.7342 and Khairuddin Tampubolon, M.Si with a score of 0.6311 are entitled to get a doctoral education scholarship from the foundation. Then subjective and computerized decisions can be obtained in this study..
\end{abstract}

Keywords: Decision Support Systems; Mysql; PHP ; Potential Lecturer Scholarships, Simple Multi Attribute Rating Technique.

\begin{abstract}
Abstrak: Peran dosen di perguruan tinggi adalah salah satu bagian paling berpengaruh dari kualitas mahasiswa yang dihasilkan. Kualifikasi pendidikan dosen juga merupakan aspek penting untuk meningkatkan kualitas akademik dan kelembagaan. Pemilihan beasiswa yayasan dalam bentuk pendidikan doktor saat ini memiliki masalah dalam memilih calon dosen. Dalam pemilihan beasiswa pendidikan doktoral untuk dosen potensial masih ada subjektivitas serta dalam seleksi mereka secara manual. Sebagai media pendukung dalam menentukan seleksi dosen potensial untuk memperoleh beasiswa yayasan pendidikan doktoral dan menguji metode SMART (Simple Multi Attribute Rating Technique) untuk memberikan rekomendasi beasiswa bagi calon dosen. Untuk proses seleksi menggunakan metode SMART karena metode ini mampu menyelesaikan masalah multi-kriteria dari yayasan dalam hal ini Rektor Universitas Pembinaan Masyarakat Indonesia. Selanjutnya, kriteria diproses menggunakan aplikasi yang dibangun menggunakan bahasa pemrograman php dan mysql untuk menguji kriteria ini. Dari aplikasi yang dibangun dapat ditarik kesimpulan bahwa Yuanita, M.Si dengan nilai 0,7342 dan Khairuddin Tampubolon, M.Si dengan nilai 0,6311 berhak mendapatkan beasiswa pendidikan doctoral dari yayasan. Kemudian keputusan subyektif dan terkomputerisasi dapat diperoleh dalam penelitian ini.
\end{abstract}

Kata kunci: Beasiswa Dosen Potensial; Mysql; PHP; Simple Multi Attribute Rating Technique; Sistem Pendukung Keputusan. 
Available online at http://jurnal.stmikroyal.ac.id/index.php/jurteksi

\section{PENDAHULUAN}

Jenjang Perguruan Tinggi adalah tingkat pendidikan setelah pendidikan menengah yang meliputi program D3, program S1, program S2, program S3, dan program profesional, serta program spesialis, yang dilaksanakan oleh kampus berdasarkan kebiasaan di Indonesia [1].

Dosen merupakan tenaga pengajar yang sangat penting dalam suatu perguruan tinggi, karena dosen banyak berperan dalam setiap kegiatan suatu perguruan tinggi. Dosen yang gelarnya lebih tinggi otomatis bisa mendorong majunya suatu kampus pada khususnya dan bangsa pada umumnya [2]. Berdasarkan (UU RI-14 tahun 2005 pasal 1 (2) Tentang Guru dan Dosen). Dalam pasal 51 ayat (1) poin b. menjelaskan bahwa dalam menjalankan tugas profesional, promosi dan penghargaan berhak didapatkan dosen berdasarkan tugas dan kinerja kerjanya [1]. Peran penting dosen untuk perguruan tinggi sangat mempengaruhi kualitas siswa yang akan dihasilkan, menciptakan siswa yang kompeten di bidangnya [3].

Sistem penghargaan dalam bentuk beasiswa yayasan pendidikan doktoral untuk dosen potensial mudah-mudahan bias jadi alternative cara untuk meningkatkan kualifikasi akademik di masingmasing universitas terutama Universitas Pembinaan Masyarakat Indoensia. Tetapi masih ada masalah subjektivitas dan belum relevan dengan situasi aktual dan masih manual dalam pemilihan beasiswa dosen potensial. Berdasarkan hal ini dalam penelitian ini dibuat untuk mendukung keputusan yang dipakai untuk melaksanakan proses seleksi untuk pemilihan dosen untuk beasiswa pendidikan doktoral dari yayasan di lembaga tersier. Sistem pendukung keputusan yang dibuat berdasarkan web memakai bahasa pem- rograman PHP dan MySQL sebagai basis data. Ini juga menjadi nilai tambah bagi Perguruan Tinggi dengan memiliki manajemen yang terkomputerisasi secara menyeluruh sebagai Pendukung nilai akreditasi kampus dengan memanfaatkan teknologi informasi hingga bagian terkecil untuk memfasilitasi kegiatan kampus [4], salah satunya adalah pemanfaatan sistem pendukung keputusan dalam memilih beasiswa beasiswa pendidikan potensial doktor. Untuk itu bisa disimpulkan bahwa masalah yang ditangani untuk pemilihan beasiswa pendidikan doktor untuk dosen potensial dari yayasan yaitu masalah subyektifitas serta pemilihanya masih secara manual.

Dalam pemilihan beasiswa pendidikan doktor dari yayasan untuk calon dosen, ada beberapa kriteria diantaranya NIDN, Masa Kerja, Pengajaran, Kualifikasi Pendidikan, Penelitian, Pengabdian, Jabatan Fungsional, dan Publikasi Jurnal.

Kemudian untuk selanjutnya akan dilakukan seleksi beasiswa pendidikan doktor, sehingga tujuan beasiswa pendidikan doktor dapat tercapai secara subyektif, optimal, terkomputerisasi dan tepat sasaran. Untuk itu, diperlukan sistem pendukung keputusan yang bisa meringankan Rektor memutuskan tentang calon dosen yang akan diberikan beasiswa pendidikan doktor. Simple Multi Attribute Rating Technique (SMART) merupakan metode system pendukung keputusan. Pembuatan alat pendukung keputusan ini memakai isyarat pemrograman PHP dan MySQL sebagai databasenya.

Sistem pendukung keputusan berfungsi untuk membantu seorang manager dalam pengambilan keptusan yang terstruktur dan setengah struktur agar lebih efektif dengan menggunakan model analitis dan data yang tersedia [5]. Proses pengambilan keputusan didukung oleh 
DOI: https://doi.org/10.33330/jurteksi.v7i1.911

Available online at http://jurnal.stmikroyal.ac.id/index.php/jurteksi

system yang inteaktif melalui alternativealternative dan Pengolahan data, informasi dan desain model berhasil diperoleh [6]. Proses pengambilan keputusan didukung oleh system yang inteaktif melalui alternative-alternative dan Pengolahan data, informasi dan desain model berhasil diperoleh .Sistem pendukung keputusan juga dapat diartikan sebagai sistem yang dirancang untuk digunakan untuk mendukung manajemen dalam pengambilan keputusan. Persoalan pengambilan keputusan, pada dasarnya adalah bentuk pemilihan dari berbagai alternatif tindakan yang mungkin dipilih yang prosesnya melalui mekanisme tertentu, dengan harapan akan menghasilkan sebuah keputusan yang terbaik. Penyusunan model keputusan adalah suatu cara untuk mengembangkan hubungan matematis, yang mencerminkan hubungan yang terjadi diantara faktor-faktor yang terlibat [7].

\section{METODE}

Penelitian ini menggunakan metode Simple Multi Atribute Rating Technique (SMART) menjadi alternative penyelesaian terhadap pendukung keputusan pemilihan beasiswa doktoral potensial. Penelitian ini dilaksanakan di $\mathrm{Jl}$. Teladan No 15, Kecamatan Medan Kota. Dalam setiap nilai alternative diprediksi linear additive yang digunakan oleh SMART [8]. SMART adalah metode pengambilan keputusan yang elastis. SMART lebih banyak digunakan karena kesederhanaannya dalam menanggapi kebutuhan pembuat keputusan dan cara menganalisis tanggapan. Teori bahwa setiap alternative didasarkan oleh teknik pengambilan keputusan multi kriteria, nilai dan setiap kriteria terdiri dari kriteria yang memiliki bobot dan ini penting dibanding dengan kriteria lain [9]. Alternatif dinilai berdasarkan bobot yang digunakan agar mendapatkan alternative terbaik [10]. Analisis yang terlibat bersifat transparan sehingga metode ini memberikan pemahaman tingkat tinggi tentang masalah dan dapat diterima oleh pembuat keputusan. Ini menggunakan data yang diperoleh dari Rektor Universitas Pembinaan Masyarakat Indonesia. Berikut ini table responden yang diperoleh dari Universitas Pembinaan Masyarakat Indonesia

Tabel 2 Responden/data dosen

\begin{tabular}{ccl}
\hline NO & NIDN & \multicolumn{1}{c}{ NAMA DOSEN } \\
\hline 1 & 0117108801 & Rini, M.T \\
\hline 2 & 0110047301 & $\begin{array}{l}\text { Khairuddin Tam- } \\
\text { pubolon, M.Si }\end{array}$ \\
\hline 3 & 0122087301 & Zetria Erma, M.H \\
\hline 4 & 0109027001 & Zulkifli, M.Si \\
\hline 5 & 0101058701 & $\begin{array}{l}\text { Reza Nurul Ichsan, } \\
\text { M.M }\end{array}$ \\
\hline 6 & 0023088702 & Sheila Hani, M.T \\
\hline 7 & 0101015712 & Yuanita, M.Si \\
\hline
\end{tabular}

Adapun langkah-langkah metode SMART adalah sebagai berikut:

Langkah 1 :Kriterai untuk dosen potensial ditentukan terlebih dahulu.

Langkah 2 : Alternatif dosen potensial ditentukan dulu.

Langkah 3 : Perengkingan dilakukan untuk menentukan kedudukan kepentinganya

Langkah 4 : Kriteria paling penting dan tidak penting diberikan bobot berdasarkan kriteria. 100 untuk bobot kriteria yang paling penting dan 10 untuk nilai bobot kriteria paling tidak penting.

Langkah 5 : Kriteria yang paling penting dan tidak penting dicari terlebih dahulu.

Langkah 6 : Berdasarkan yang paling penting dan tidak penting bobot kriteria dicari rata- 
Available online at http://jurnal.stmikroyal.ac.id/index.php/jurteksi

ratanya. Setiap kriteria diberikan bobot pada setiap alternative.0-100 merupakan bobot aternatif. 100 merupakan nilai maksimun dan 0 nilai minimum.

Langkah 7 : Penilaian/utilitas dihitung menggunakan rumus terhadap setiap alternative.rumus 1 [11].

$$
S M A R T=\sum_{j=1}^{k} w_{j} u_{i j}
$$

Dimana :

a. $W_{j}$ kriteria ke - j dari k merupakan nilai pembobotan

b. Uij alternative i pada kriteria $\mathrm{j}$ adalah nilai utiliy

c. Identifikasi nilai fungsi terbesar dari $n$ alternative .

d. Alternatif $n$ dirangking menggunakan nilai fungsi

Menghitung nilai normalisasi bobot :

$$
n w_{j}=\frac{w_{j}}{\sum_{n=1}^{k} w_{n}}
$$

a. $n w_{j}$ adalah nilai normalisasi bobot kriteria ke $-\mathrm{j}$

b. $w_{j}$ adalah nilai bobot kriteria $\mathrm{ke}-\mathrm{j}$

c. $k$ adalah jumlah kriteria

d. $w_{n}$ adalah bobot kriteria ke $-\mathrm{n}$

Menghitung nilai utiliti :

$$
u_{i j}=f\left(v_{i j}\right)
$$

a. $u_{i j}$ adalah nilai utiliti kriteria ke j untuk alternatif $\mathrm{i}$

b. $\quad v_{i j}$ adalah nilai kriteria $\mathrm{ke}-\mathrm{j}$ untuk altefnatif $i$

c. $f\left(v_{i j}\right)$ adalah fungsi kriteria ke $-\mathrm{j}$ untuk alternatif $i$ [12].

Berikut urutan penggunaan metode SMART :

1. Bayaknya kriteria yang digunakan ditentukan terlebih dahulu .

2. Kriteria paling penting dan tidak penting diberikan bobot berdasarkan kriteria. 100 untuk bobot kriteria yang paling penting dan 10 untuk nilai bobot kriteria paling tidak penting.

3. Bandingkan nilai bobot kriteria dan jumlah bobot kriteria kemudian hitung normalisasinya, Menggunakan rumus :

Normalisasi $=\frac{w_{J}}{\sum w_{J}}$

Dimana $W_{j}$ adalah nilai bobot dari suatu kriteria. Sedangkan, $\Sigma W_{J}$ adalah total jumlah bobot dari semua kriteria.

4. Setiap alternative pada setiap kriteria diberikan nilai parameter.

5. Data baku dari nilai kriteria diberikan nilai utility kemudian dikonversi nilai kriteria pada masing -masing kriteria. Persamaan nilai utility diperoleh menggunakan rumus berikut

$$
u_{i}\left(a_{i}\right)=\frac{c_{\text {out }}-c_{\min }}{c_{\max }-c_{\min }}
$$

Dimana $u_{i}\left(a_{i}\right)$ adalah nilai utiliti kriteria ke 1 untuk kriteria ke - I, $c_{\max }$ adalah nilai kriteria maksimal, $c_{\min }$ adalah nilai kriteria minimal dan $c_{\text {out }}{ }^{i}$ adalah nilai kriteria $\mathrm{ke}-\mathrm{i}$.

Maka didapat nilai tersebut adalah :

$c_{\text {out }} i=u_{i}\left(a_{i}\right)=0 ; 2=0,5: 3=1$

6. Nilai normalisasi bobot kriteria didapat dari normalisasi mengalihkan masingmasing nilai yangsudah ditentukan. Perkalian tersebut dijumlahkan .

$$
u\left(a_{i}\right)=\sum_{J=1}^{m} w_{j} u_{i}\left(a_{i}\right)
$$

Dimana $u\left(a_{1}\right)$ adalah nilai total alternatif, $w_{j}$ adalah hasil dari normalisasi bobot kriteria dan $u_{i}\left(a_{i}\right)$ adalah hasil penentuan utility [13]. 
DOI: https://doi.org/10.33330/jurteksi.v7i1.911

Available online at http://jurnal.stmikroyal.ac.id/index.php/jurteksi

\section{HASIL DAN PEMBAHASAN}

Pada penelitian ini penulis menggunakan 7 sampel dosen dalam pemilihan beasiswa doctor potensial. Berikut sample data Dosen yang digunakan pada penelitian ini, yaitu :

Tabel 3 Tabel Alternatif/Data Dosen

\begin{tabular}{ccl}
\hline NO & NIDN & \multicolumn{1}{l}{ NAMA DOSEN } \\
\hline 1 & 0117108801 & Rini, M.T \\
\hline 2 & 0110047301 & $\begin{array}{l}\text { Khairuddin Tam- } \\
\text { pubolon, M.Si }\end{array}$ \\
\hline 3 & 0122087301 & Zetria Erma, M.H \\
\hline 4 & 0109027001 & Zulkifli, M.Si \\
\hline 5 & 0101058701 & $\begin{array}{l}\text { Reza Nurul Ichsan, } \\
\text { M.M }\end{array}$ \\
\hline 6 & 0023088702 & Sheila Hani, M.T \\
\hline 7 & 0101015712 & Yuanita, M.Si \\
\hline
\end{tabular}

Adapun jumlah kriteria berdasarkan data hasil wawancara dengan Rektor Universitas Pembinaan Masyarakat Indonesia Medan, kriteria yang menjadi point penilaian berjumlah 8 kriteria yaitu :a)Masa Kerja, b)Pengajaran, c)Kualifikasi Pendidikan, d)Penelitian, e)Pengadian, f)Jabatan Fungsional, g)Publikasi Jurnal, h)NIDN. Selanjutnya memberikan Skala prioritas normalisasi bobot dilakukan untuk menentukan preferensi pada setiap kriteria.

Tabel 4. Kriteria dan Bobot

\begin{tabular}{cll}
\hline KODE & \multicolumn{1}{c}{ KRITERIA } & BOBOT \\
\hline C1 & Masa Kerja & 70 \\
\hline C2 & Pengajaran & 80 \\
\hline C3 & Kualifikasi Pendidikan & 75 \\
\hline C4 & Penelitian & 80 \\
\hline C5 & Pengabdian & 80 \\
\hline C6 & Jabatan Fungsional & 80 \\
\hline C7 & Publikasi Jurnal & 85 \\
\hline C8 & NIDN & 60 \\
\hline & JUMLAH & 610 \\
\hline
\end{tabular}

Selanjutnya normalisasi bobot dilakukan dengan menggunakan rumus :

$$
N i=\frac{W i}{\sum W i}
$$

Tabel 5 Normalisasi Nilai Bobot Kriteria

\begin{tabular}{|c|c|c|c|}
\hline Kode & Kriteria & Bobot & $\begin{array}{l}\text { Nil. Nor- } \\
\text { malisasi }\end{array}$ \\
\hline $\mathrm{C} 1$ & Masa Kerja & 70 & $\begin{array}{l}70 / 610= \\
0,1148\end{array}$ \\
\hline $\mathrm{C} 2$ & Pengajaran & 80 & $\begin{array}{l}80 / 610= \\
0,1311\end{array}$ \\
\hline $\mathrm{C} 3$ & $\begin{array}{l}\text { Kualifikasi } \\
\text { Pendidikan }\end{array}$ & 75 & $\begin{array}{l}75 / 610= \\
0,123\end{array}$ \\
\hline C4 & Penelitian & 80 & $\begin{array}{l}80 / 610= \\
0,1311\end{array}$ \\
\hline $\mathrm{C} 5$ & Pengabdian & 80 & $\begin{array}{l}80 / 610= \\
0,1311\end{array}$ \\
\hline C6 & $\begin{array}{l}\text { Jabatan } \\
\text { Fungsional }\end{array}$ & 80 & $\begin{array}{l}80 / 610= \\
0,1311\end{array}$ \\
\hline $\mathrm{C} 7$ & $\begin{array}{l}\text { Publikasi } \\
\text { Jurnal }\end{array}$ & 85 & $\begin{array}{l}85 / 610= \\
0,1393\end{array}$ \\
\hline $\mathrm{C} 8$ & NIDN & 60 & $\begin{array}{l}60 / 610= \\
0,0984\end{array}$ \\
\hline & JUMLAH & 610 & \\
\hline
\end{tabular}

Setelah itu menentukan nilai dari Alternatife. Untuk mendapat nilai alternatife kriteria berdasarkan wawancara dengan Rektor Universitas Pembinaan Masyarakat Indonesia dapat dilihat di table 5. Selanjutnya adalah nilai table utility. Selanjutnya tahap ini akan di uji coba 7 dosen yang berpotensi mendapat beasiswa pendidikan doctor dapat dilihat pada table 7 . 
JURTEKSI (Jurnal Teknologi dan Sistem Informasi)

Vol. VII No. 1, Dec 2020, hlm. 39 - 46

DOI: https://doi.org/10.33330/jurteksi.v7i1.911

Available online at http://jurnal.stmikroyal.ac.id/index.php/jurteksi

Tabel 6. Data Alternatife

\begin{tabular}{llcccccccc}
\hline NO & \multicolumn{1}{c}{ NAMA DOSEN } & C1 & C2 & C3 & C4 & C5 & C6 & C7 & C8 \\
\hline A2 & Yuanita, M.Si & 72 & 83 & 78 & 78 & 73 & 82 & 78 & 59 \\
A3 & Khairuddin Tampubolon, M.Si & 70 & 80 & 75 & 80 & 80 & 85 & 80 & 60 \\
A4 & Zetria Erma, M.H & 70 & 80 & 75 & 75 & 80 & 80 & 75 & 60 \\
A5 & Sheila Hani, M.T & 70 & 80 & 75 & 80 & 75 & 75 & 80 & 60 \\
A6 & Reza Nurul Ichsan, M.M & 70 & 80 & 75 & 80 & 70 & 75 & 75 & 60 \\
A7 & Zulkifli, M.Si & 70 & 80 & 75 & 75 & 70 & 70 & 70 & 60 \\
A8 & Rini, M.T & 70 & 80 & 75 & 70 & 75 & 70 & 68 & 60 \\
\hline
\end{tabular}

Tabel 7. Data Utility

\begin{tabular}{|c|c|c|c|c|c|c|c|c|c|c|c|}
\hline \multicolumn{3}{|c|}{ NAMA DOSEN } & $\mathrm{C} 1$ & $\mathrm{C} 2$ & C3 & $\mathrm{C} 4$ & & C5 & C6 & C7 & C8 \\
\hline \multicolumn{3}{|l|}{ Yuanita, M.Si } & 0 & 0 & 1 & 1 & & 0 & 0 & 0.5 & 0 \\
\hline \multicolumn{3}{|c|}{ Khairuddin Tampubolon, M.Si } & 0 & 0.6 & 0 & 0 & & 0 & 0 & 0 & 0 \\
\hline \multicolumn{3}{|c|}{ Zetria Erma, M.H } & 0 & 1 & 0 & 0.28 & & 0.4 & 1 & 0.3 & 1 \\
\hline \multicolumn{3}{|c|}{ Sheila Hani, M.T } & 0 & 0.6 & 1 & 1 & & 1 & 1 & 0.5 & 0.5 \\
\hline \multicolumn{3}{|c|}{ Reza Nurul Ichsan, M.M } & 0 & 1 & 0.5 & 0.14 & & 0 & 1 & 1 & 0 \\
\hline \multicolumn{3}{|l|}{ Zulkifli, M.Si } & 0.25 & 0 & 0.3 & 0.71 & & 0.6 & 1 & 0.5 & 0 \\
\hline \multicolumn{3}{|l|}{ Rini, M.T } & 1 & 1 & 0.8 & 0.28 & & 0 & 1 & 0.5 & 1 \\
\hline \multicolumn{12}{|c|}{ Tabel 8. Uji Coba } \\
\hline \multicolumn{12}{|l|}{ DOSEN } \\
\hline Yuanita, M.Si & 0.1148 & 0.1311 & 0.123 & 0.1049 & \multicolumn{2}{|c|}{0.0393} & \multicolumn{2}{|c|}{0.1049} & 0.1161 & \multicolumn{2}{|l|}{0} \\
\hline \multicolumn{3}{|l|}{$\begin{array}{l}\text { Knairudain } \\
\text { Tampubolon, } \\
\text { M.Si }\end{array}$} & 0 & 0.1311 & \multicolumn{2}{|c|}{0.1311} & \multicolumn{2}{|c|}{0.1311} & 0.1393 & \multicolumn{2}{|c|}{0.0984} \\
\hline $\begin{array}{l}\text { Zetria Erma, } \\
\text { M.H }\end{array}$ & 0 & 0 & 0 & 0.0656 & \multicolumn{2}{|c|}{0.1311} & \multicolumn{2}{|c|}{0.0874} & 0.0813 & \multicolumn{2}{|c|}{0.09} \\
\hline $\begin{array}{l}\text { Sheila Hani, } \\
\text { M.T }\end{array}$ & 0 & 0 & 0 & 0.1311 & \multicolumn{2}{|c|}{0.0656} & \multicolumn{2}{|c|}{0.0437} & 0.1393 & \multicolumn{2}{|c|}{0.0984} \\
\hline $\begin{array}{l}\text { Reza Nurul } \\
\text { Ichsan, M.M }\end{array}$ & 0 & 0 & 0 & 0 & \multicolumn{2}{|c|}{0.1311} & \multicolumn{2}{|l|}{0} & 0.0437 & \multicolumn{2}{|c|}{0.0813} \\
\hline Zulkifli, M.Si & 0 & 0 & 0 & 0 & \multirow{2}{*}{\multicolumn{2}{|c|}{0.0656}} & \multicolumn{2}{|l|}{0} & 0 & \multicolumn{2}{|c|}{0.0232} \\
\hline Rini, M.T & 0 & 0 & 0 & 0 & & & 0 & & 0 & & 884 \\
\hline
\end{tabular}

Berikut ini adalah tabel perengkingan didapatkan dua orang yang berpotensi mendapatkan beasiswa pendidikan doctor yaitu Yuanita, M.Si dengan Khairuddin Tampubolon, M.Si. 
DOI: https://doi.org/10.33330/jurteksi.v7i1.911

Available online at http://jurnal.stmikroyal.ac.id/index.php/jurteksi

Tabel 8. Perengkingan

\begin{tabular}{ccc}
\hline NAMA DOSEN & TOTAL & $\begin{array}{c}\text { RENG- } \\
\text { KING }\end{array}$ \\
\hline Yuanita, M.Si & 0.7342 & 1 \\
\hline Khairuddin Tampubolon, M.Si & 0.6311 & 2 \\
\hline Zetria Erma, M.H & 0.4781 & 3 \\
\hline Sheila Hani, M.T & 0.4638 & 4 \\
\hline Reza Nurul Ichsan, M.M & 0.3545 & 5 \\
\hline Zulkifli, M.Si & 0.1872 & 6 \\
\hline Rini, M.T & 0.1639 & 7 \\
\hline
\end{tabular}

\section{SIMPULAN}

Proses perhitungan dengan menggunakan metode SMART berdasarkan kriteria (masa kerja, pengajaran, kualifikasi pendidikan, penelitian, pengabdian, jabatan fungsional, publikasi jurnal dan NIDN) dari 7 data responden/data alternatif diperoleh urutan nilai dari yang tertinggi sampai terendah. Adapun prioritas urutan 2 orang dosen penerima beasiswa pendidikan doktoral adalah Yuanita, M.Si dengan skor 0.7342 dan Khairuddin Tampubolon, M.Si dengan skor 0,6311.

\section{UCAPAN TERIMA KASIH}

Terimakasih diucapkan kepada Direktorat Riset dan Pengabdian Masyarakat Deputi Bidang Penguatan Riset dan Pengembangan Kementerian Riset dan Teknologi / Badan Riset dan Inovasi Nasional yang telah mensetujui dan mendanai penelitian ini.

\section{DAFTAR PUSTAKA}

[1] M. Sanwasih and S. A. Setyawan, "Kinerja Dosen Terbaik Dengan Algoritma Weighted Product Berbasis Web ( Studi Kasus: Fakultas Teknik Universitas Islam At-Tahiriyah )," pp. 13-18, 2018.

[2] A. S. Kurniawansyah, J. Wahyudi, and R. Julita, "Membangun Sistem Pendukung Keputusan Untuk Menentukan Dosen Berprestasi Di Prodi Informatika Fakultas Ilmu Komputer Universitas Dehasen Bengkulu," vol. 15, no. 1, pp. 4449, 2019.

[3] N. Marpaung, M. Handayani, and R. Yesputra, "Sistem Pendukung Keputusan Pemilihan Dosen Terbaik Dengan Metode Weighted Product (WP) Pada STMIK Royal," Semin. Nas. R. 2018, vol. 9986, no. September, pp. 267-270, 2018.

[4] Ardi, ANDROID \& KRIPTOGRAFI ALGORITMA RIVESTCODE 6,REKAYASA PERNGKAT LUNAK, SMS, 1 st ed. Medan: CV. SENTOSA DELI MANDIRI, 2020. 
D. Aldo and Ardi, "Sains dan Teknologi Informasi Sistem Pakar Diagnosa Penyakit Limfoma dengan Metode Certainty Factor," vol. 5, no. 1, 2019.

[6] A. D. C. Ari Basuki, Sistem Pendukung Keputusan, Edisi 1. Yogyakarta: deep, 2016.

[7] S. H. A. Lita Asyriati Latif, Mohammad Jamil, Sistem Pendukung Keputusan Teori dan Aplikasi. deepublish, 2018.

[8] Z. Azhar, "Penentuan Penempatan Karyawan Baru Di PDAM Kisaran Dengan Metode SMART," JURTEKSI (Jurnal Teknol. dan Sist. Informasi), vol. Vol.4,No.2, no. (Juni, ISSN: 2407-1811), pp. 179-184, 2018, [Online]. Available:

http://jurnal.stmikroyal.ac.id/index .php/jurteksi.

[9] H. Sibyan, "Implementasi Metode SMART pada Sistem Pendukung Keputusan Penerima Beasiswa Sekolah," J. Penelit. dan Pengabdi. Kpd. Masy. UNSIQ, vol. 7, no. 1, pp. 78-83, 2020, doi: 10.32699/ppkm.v7i1.1055.

[10] D. Y. H. Tanjung and R. Adawiyah, "Perancangan Sistem Pendukung Keputusan Dengan Metode Simple Multi Attribute
Rating Technique ( SMART ) Dalam Penilaian Kinerja Dosen ( Studi Kasus: Universitas Potensi Utama )," IT J., vol. 6, pp. 149159, 2018.

[11] M. Hayaty and R. F. Irawan, "Perancangan Sistem Penunjang Keputusan untuk Menentukan Jabatan Pengurus Organisasi Menggunakan Kombinasi Algoritma Simple Multi Attribute Rating Technique (SMART) dan Forward Chaining," Khazanah Inform. J. Ilmu Komput. dan Inform., vol. 4, no. 2, p. 104, 2018, doi: 10.23917/khif.v4i2.7034.

[12] Z. Yunizar, "Sistem Pendukung Keputusan Penentuan Lokasi Pembuatan Batu Bata Menggunakan Metode Smart," Maj. Ilm. Univ. Almuslim, vol. 10, pp. 73-78, 2018.

[13] D. Novianti, I. Fitri Astuti, and D. M. Khairina, "Sistem Pendukung Keputusan Berbasis Web Untuk Pemilihan Café Menggunakan Metode Smart (Simple MultiAttribute Rating Technique) (Studi Kasus : Kota Samarinda)," Pros. Semin. Sains dan Teknol. FMIPA Unmul, vol. 1, no. 3, pp. 461-465, 2016. 